\title{
PROCESS OF TECHNOLOGY MANAGEMENT IN SMES OF THE METAL PROCESSING INDUSTRY - THE CASE STUDY INVESTIGATION
}

\author{
ELŻBIETA KRAWCZYK-DEMBICKA
}

\begin{abstract}
A B S T R A C T
The main purpose of this work is to identify the factors that influence the process of technology management in the sector of small- and medium-sized enterprises of the metal processing industry, considering the shape and course required to achieve modern operation conditions by enterprises in the market.

The research process used the case study method, which was preceded by study visits to manufacturing enterprises, direct interviews with representatives of the management and employees of enterprises, and observations of the processing conditions.

The result of the research was the identification of technologies available and used in the analysed enterprises. It defines the process of technology management as well as the internal and external factors influencing this process and defines the timeline for the process of technology management.

The obtained results are the effect of the preliminary research, whose outcome will result in the development of issues related to technology management. They will be used to create a model of technology management, the assumptions of which will respond to modern needs and possibilities of manufacturing enterprises of the metal processing industry. The model can be used for practical application aimed at the provision of enterprises with innovation and competitiveness in the domestic and foreign markets.
\end{abstract}

KEY WORDS

technology management, models, metal processing industry, production enterprise

DOI: 10.1515/emj-2017-0002
Corresponding author:

Elżbieta Krawczyk-Dembicka

Bialystok University of Technology, Faculty of Management, Department of Organisation and Management, Poland

e-mail: e.dembicka@pb.edu.pl

\section{INTRODUCTION}

In modern enterprises of the metal processing industry, technology management is conditioned by company size and level of its competitiveness in the market. The bigger is the company, the more advanced is the level of development of the company. The same applies to the situation with technologies. Usually, companies from the sector of small- and medium- sized enterprises use the technologies available to the market, acquiring them together with purchased machinery and equipment and tailoring them to individual needs that depend on the profile of the business. Large companies usually develop their own technologies.

Manufacturing enterprises often perceive technologies as a possibility of using available processes 
and the technological operation to create new products and meet the market demand. The research problem is, therefore, to determine how to define the technologies and the technology management.

The purpose of this study is the identification of external and internal factors influencing the technology management process in small- and mediumsized enterprises operating in the metal processing industry.

The study employs a case study methodology. Several data collection methods were utilized to prepare for the case study, i.e. direct observation (study visits), analysis of the enterprise documents, analysis of the archive materials, and direct interviews. Various sources of information considered during the formulation of conclusions of the study.

\section{REVIEW OF THE LITERATURE ON TECHNOLOGY MANAGEMENT ${ }^{1}$}

The development of manufacturing enterprises depends on their level of competitiveness in world markets. The level is largely conditioned by the access to technology and the ability to introduce innovative solutions. The correct integration of technologies in an enterprise should, therefore, be a source of a sustainable competitive advantage (Ejdys et al., 2015; Song et al., 2013). For this purpose, it is necessary both to understand the nature of technology as well as to determine the mechanisms shaping the process of technology management (Halicka, 2016; Mazurkiewicz et al., 2015).

Technology is a component of general knowledge on the types of techniques, methods of their formation, and practical implementation. It leads to gaining knowledge (often hidden or forbidden) and skills related to solving specific technological problems. In the literature, there are many different technology definitions relating to both its scientific significance and practical application. Cornwall (1977) defines technology as a resource of knowledge relating principally to the production of goods and services. Rosenberg (1982), in turn, talks about the under-

\footnotetext{
1 The chapter contents come from the introduction to the article to be published in Procedia Engineering (2017) as conference materials of the 7 th International Conference on Engineering, Project and Production Management, Poland, Bialystok, September 21-23, 2016. The original work: E. Krawczyk-Dembicka, Analysis of technology management using the example of the production enterprise from the SME sector.
}

standing and implementation of previously acquired scientific knowledge on the types of techniques, methods, and structures. Dosi (1984) combines these two definitions and defines technology as a set of elements of practical and theoretical knowledge, skills of its application (know-how), methods, procedures and physical devices that use this knowledge. Polish authors predominantly define technology as the knowledge of manufacture methods required to produce a given product. In his work, Łunarski defines technology as "a directed process of producing the necessary products and services, implemented in a hierarchical production system with identified elements and their relationships, built for the realization of this process on the basis of the available theoretical and practical knowledge" (Lunarski, 2009, p. 202). The process approach to the subject is also presented by Santarek, who claims that technology is "a process consisting of many activities carried out in a strictly defined manner and sequence, resulting in the processing of input goods (raw materials, semi-finished products) into finished products having certain features and meeting customer needs" (Santarek, 2008, pp. 7-8).

From the definitions present in the literature as well as the amount and variety of technology existing on the market and the role that it fulfils in the modern economy, stems the need to develop mechanisms for technology management. The term technology management has been defined, among others by a team of researchers from the US National Research Council, which concluded that Technology Management (TM) combines the disciplines of engineering sciences and management sciences with the purpose of planning, development and implementation of technological capabilities, which will enable the implementation of strategic and operational objectives of the organisation (NRC, 1987, p. 2). The NRC team has also defined the key elements of technology management, which served other researchers in building the models of technology management. These are:

- identification and evaluation of technological options;

- project R\&D management and the determination of its feasibility;

- integration of technologies into activities of the organisation;

- implementation of new technologies into products and/or services;

- obsolescence and replacement of technology.

One of the first authors carrying out research on the formulation of the model of technology manage- 
ment was Gregory (1995, p. 350). He proposed a general model, including five major activities in the field of technology management of an enterprise, among which it is possible to distinguish identification, selection, acquisition, operation and protection of technology. Within each of the five activities, it is possible to extract several additional elements that, depending on the industry, will be subject to change. Within the framework of the technology identification process it is important to conduct a market analysis of the available technologies and find those that could have a significant impact on the development of the company. The next step is the selection and acquisition of the appropriate technology. All the activities related to the identification, selection, and acquisition of technology may take place inside or outside the company. The essential role is played by the human, technological and financial potential, at the disposal of a given entity. The other two activities (exploitation and protection of technology) are dependent solely on the conditions within the company and have an enormous impact on the generation of enterprise competitiveness.

Gregory's model has been supplemented or modified multiple times by other researchers. In most of the models, the differences are slight and limited to the change in classification and the recognition of the scope of individual activities. The differences also stem from the different understanding of some of the definitions. This indicates a lack of the ability to accurately classify concepts in the field of innovation management, knowledge management, and technology management. The common feature of all the described in the literature models is the determination of the general framework of technology management.

New insights are brought by researchers Pelser \& Prinsloo (2014, p. 1), who noted that technology plays an important role in the interaction between entities (companies, research and development units), society and nature. Thus, they concluded that the current technological advances in the world could have serious implications for each of these entities and depend on their impact. Therefore, they agreed that technology management should be based on the development of the understanding of the issues concerning the relationships between individual units and identifying ways to rationally and efficiently utilize them.

The models currently described in the literature do not include the conditions prevailing in the modern economy. They do not define a clear process of the technology management but rather indicate its existence. The author of this work has undertaken to identify the factors that influence the process of the technology management in small-and-medium enterprises of the metal processing industry. This work leads to finding the common activities and relationships that create the process of technology management in the industry, independent of the size and structure of the company, but in relation to other variables, such as the cooperation between companies. The technology definition used in this study refers to the application of the knowledge on metal processing processes to the selection and modification of the production operations that are used in companies.

\section{RESEARCH METHODS}

Three study visits to each of the analysed manufacturing enterprises of the metal processing industry were carried out from June to September. During the visits, direct interviews were conducted with representatives of the company's management. In addition, documents made available by the enterprises were analysed. The collected information was supplemented by observations made in the various production departments. The research helped to identify several key factors influencing the manner of the technology management in small- and medium-sized enterprises.

The results are described in the case study of the enterprises. The basis for the formulation of the assumptions of the study was a critical analysis of literature. As a result, we selected three main elements, that created the structure of the case study:

1. characteristics of the enterprise and available technologies;

2. the manner of technology management in the enterprise;

3. the decision-making in the technology management.

The structure of the research process is shown in Fig. 1.

The section that includes the characteristics of enterprises and available technologies, analyses the functioning of the metal processing industry enterprise, identifies the types of technologies used, and studies their source of origin and funding.

The next stage was to determine the activities that are characteristic of the process of technology management already being used in the enterprise. 


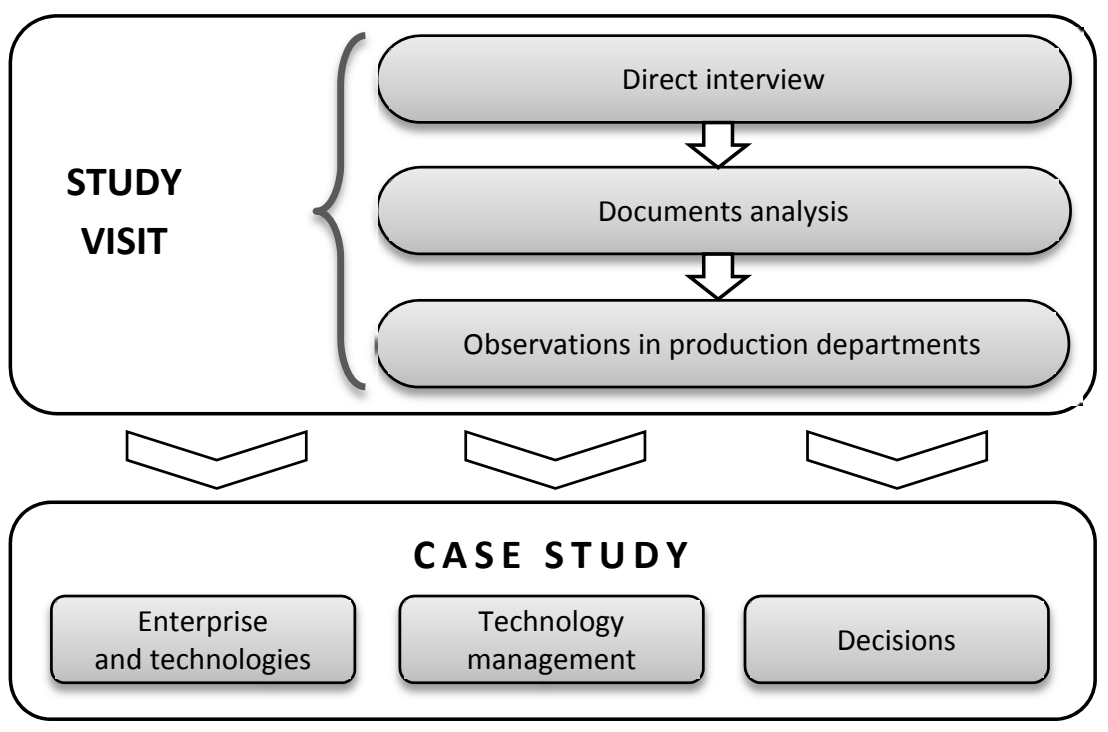

Fig. 1. Structure of the research process company employs about 70 people and belongs to the group of mediumsized businesses.

The common factor connecting both enterprises is their policy, covering similar objectives and core values (Fig. 2). In general, they can be placed in one of these five main areas (1) the dialogue with customers and their satisfaction with the received products; (2) a well-supplied offer adapted to individual needs and customer requirements; (3) high
The last stage was to determine the organisational structure of an enterprise, study who and at what stage of the process has the key influence on the decision-making, and to identify the factors that regulate the process of technology management.

\section{RESEARCH RESULTS}

For the needs of this study, two case studies of manufacturing enterprises of the metal processing industry were described, namely, one small and one medium company. The enterprises operate in Polish and foreign markets, have an outlined organisational structure, clearly defined development goals of the company, and formulated values. They use similar technologies.

The first of the analysed enterprises is a manufacturer of decorative and functional metal products. They are used in homes, gardens, and public places. The main customers of the company are trading networks, wholesale and landscape architects from the European Union and Eastern Europe. The company employs about 40 people. Considering the financial turnover, the company belongs to the group of small businesses.

The second of the surveyed enterprises is a manufacturer of machinery and technological equipment, used, among other things, in the construction of production lines. The enterprise also provides machining services for local entrepreneurs. Major customers are industrial concerns and the food industry. The efficiency of production that ensures the timeliness of orders; (4) taking care of the highest quality of products and services, and (5) investments into staff development and application of various types of motivating schemes to increase the employee involvement. One important element is the values respected within enterprises: (1) the knowledge and skills enabling the most innovative projects; (2) the effective teamwork ensuring proper implementation of the production process; (3) the involvement in the implementation of the enterprise goals, which has positive effects on the quality of solutions; (4) the aspiration for the permanent expansion of the company and investments in staff development; and (5) the safety and quality processing.

Analysis of the organisational structure of the enterprises unveils many similarities (Fig. 3). The management board is the governing body with one of the members acting as the technical director. The structure of enterprises has two main divisions: the Department of Economics, which includes the Human Resources Department and the Sales Department, and the Engineering Department, which has the Project Department, the Technology Department, the Production Department and the Storage Department.

This structured scheme provides a clear division of responsibilities of various departments and has an impact on the speed of decision-making. The expansion of the organisational structure has an influence on the time and the level of decision-making. The more complex is the structure, the more decision-making processes are needed at lower levels. 


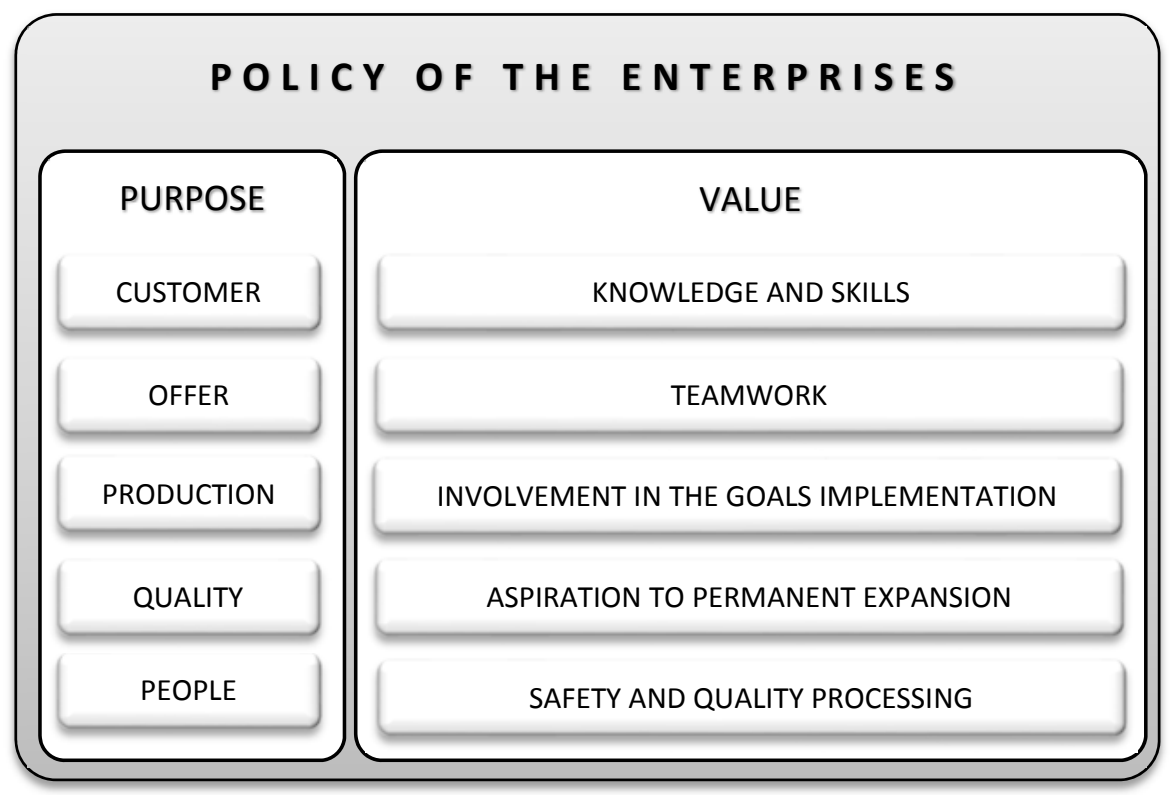

Fig. 2. Structure of the company policy Source: own study based on company's materials.

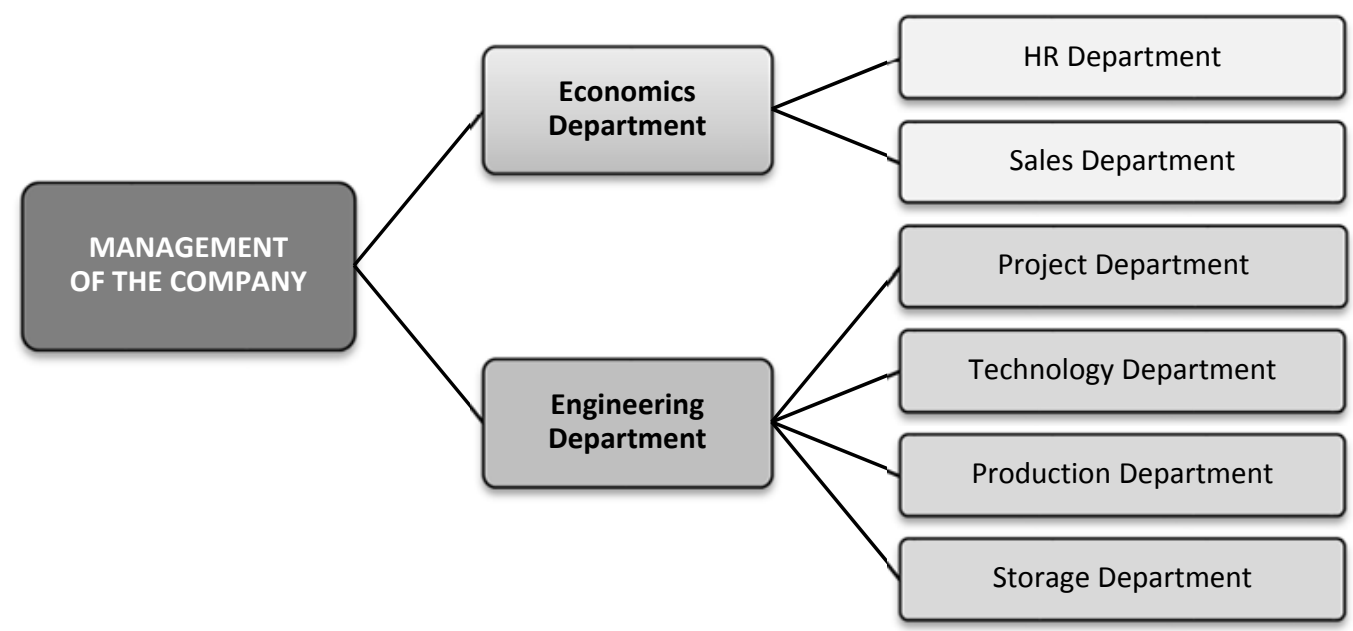

Fig. 3. General framework of organisational structure of enterprises Source: own study based on enterprises materials.

The study visits and staff interviews identified several technologies used in the enterprises (Tab. 1).

Implementation of the technologies was associated with the use of ready-made solutions, commonly available in the market, such as the 5-axis milling. It was related to the purchase of new machinery and equipment necessary to fulfil orders placed by customers. Often, this resulted in the adjustment of the purchased machines for needs of the individual enterprise. The source of funding for new technologies was, in most cases, self-funding. This does not exclude public funding in the form of aid for modernization and expansion of production halls and equipment. The European Union support accounted for a small percentage of all spent funds. The implementation of new technologies is mainly determined by economic factors. As an enterprise has no visible evidence of the capabilities of a technology producing another product, it usually decides against their purchase.

The purpose of the study was to determine the process of developing a new technology, which would give the view of process technology management on the scale of the whole production and describe the work of enterprises. The process with the time perspective of individual activities is given in Fig. 4 . The execution time of this process is from 3 to 6 months. 
Tab. 1. Types of metal processing identified in enterprises

\begin{tabular}{|l|l|}
\hline \multicolumn{1}{|c|}{ TECHNOLOGY GROUPS } & \multicolumn{1}{c|}{ TYPES OF TECHNOLOGY } \\
\hline \multirow{2}{*}{ Surface treatment } & - turning \\
& - milling \\
& - drilling \\
\hline \multirow{2}{*}{ Locksmithing treatment } & - semi-automatic and automatic \\
& - grinding \\
\hline \multirow{2}{*}{ Profiling treatment } & - cutting sheets (water, laser, \\
& - scissors, wire) \\
& - cutting profiles (bandsaw) \\
\hline Other & - forming \\
\hline Thermal treatment & - rolling \\
\hline & - grooving \\
\hline
\end{tabular}

\begin{tabular}{|c|c|}
\hline Customer need for a new pr & 1 day \\
\hline Analysis of the feasibility of the order & $1-2$ weeks \\
\hline $\begin{array}{l}\text { - analysis of the potential of the enterprise } \\
\text { - consultation with the customer }\end{array}$ & \\
\hline Designing the technology, following preliminary guidelines of the & 4-8 weeks \\
\hline - consultation with the customer & \\
\hline Analysis and verification a correct construction & 1 week \\
\hline Identification of the technological possibilities offered by the market & $1-2$ weeks \\
\hline $\begin{array}{l}\text { - analysis of the patent databases } \\
\text { - trade shows } \\
\text { - Internet }\end{array}$ & \\
\hline
\end{tabular}

Selection of the appropriate technology and the preparation of the technical documentation

- acquisition of the necessary technologies and their adaptation to individual needs

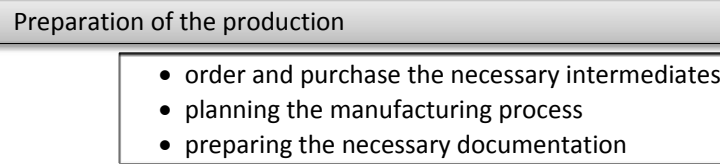

- order and purchase the necessary intermediates

- planning the manufacturing process

- preparing the necessary documentation

Exploitation of the technology - implementation of the manufacturing process

- execution of details

- installation

- quality control

- testing of the product

- analysis of the product, elimination of errors and faults

- sales of the product

The search for new possibilities for the use of the technology
The method of the process management depends on several external and internal factors that affect the conditions of the enterprise. The most important internal factors include:

- qualifications of the enterprise workers;

- technological possibilities of the company;

- financial capabilities of the company related to the acquisition of new technologies;

- the economic viability of implementation of the new technologies;

- the scope of ongoing contracts;

- the size of production series;

- the available machinery park;

- manufacturing capabilities of the enterprise;

- quality factors of the used technologies.

Apart from internal factors, the external factors also play an important role, which shows the impact of the environment on the functioning of the company in the market. These include:

- the possibility to acquire technology from the market;

- possibilities of cooperation with other production enterprises in the industry; 
- the market prices of purchase machinery, equipment, materials, technologies (the costs of introducing new technology);

- possibilities of adaptive technology to other objectives realised by the enterprises.

The above-mentioned factors are an important element influencing on the shape and course of the process of technology management, in production enterprises from the metal processing industry in the sector of small- and medium-sized enterprises. They correspond to different turbulence in the industry and describe the environment of the company.

\section{CONCLUSIONS}

In small- and medium-sized enterprises from the metal processing industry, the linear process of technology management is clear. This process is the part of the manufacturing process, which aims to produce a new product, corresponding to the clearly defined requirements and customer needs. Enterprises are guided primarily by economic factors that determine the cost effectiveness of the acquisition and implementation of new technologies, as well as the possibility of its adaptation for other goals of the companies.

All decision-making processes related to technology management are in the hands of the company management. They are dependent on the size and organisational structure. The more complex is the structure, the more decision-making processes are needed at lower levels, and the management focuses mainly on the financial decisions concerning the acquisition of new technologies. The Management also has the final say on the implementation of the technologies. The possibility of adaptive technologies that are available in an enterprise is influencing the development of new products and technologies.

\section{ACKNOWLEDGEMENTS}

The research has been carried out in the framework of the work G/WZ/1/2016 and financed by the National Science Centre (agreement No. 2015/19/N/HS4/02576).

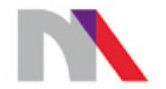

\section{Ministry of Science} and Higher Education

Republic of Poland

7th International Conference on Engineering, Project, and Production Management (EPPM2016) was financed in the framework of the contract no. 712/P-DUN/2016 by the
Ministry of Science and Higher Education from the funds earmarked for the public understanding of science initiatives.

7th International Conference on Engineering, Project, and Production Management (EPPM2016) finansowana w ramach umowy 712/P-DUN/2016 ze środków Ministra Nauki i Szkolnictwa Wyższego przeznaczonych na działalność upowszechniającą naukę.

\section{LITERATURE}

Cornwall, J. (1977). Modern Capitalism: Its Growth and Transformation. London, Great Britain: Martin Robertson.

Dosi, G. (1984). Technical Change and Industrial Transformation. London, Great Britain: The Macmillan Press Ltd.

Ejdys, J., Ustinovicius, L., \& Stankevičienè. J. (2015). Innovative application of contemporary management methods in a knowledge-based economy - interdisciplinarity in science. Journal of Business Economics and Management, 16(1), 261-274. doi:10.3846/16111 699.2014.986192

Gregory. M. J. (1995). Technology management: a process approach. Proceedings of the Institution of Mechanical Engineers, 209, 347-356.

Halicka, K. (2016). Innovative Classification of Methods of The Future-Oriented Technology Analysis. Technological and Economic Development of Economy, 22(4), 574-597. doi: 10.3846/20294913.2016.1197164

Krawczyk-Dembicka, E. (2016). Analysis of technologies management on the example of the production enterprise from the SME sector. Procedia Engineering, Conference paper of the 7th International Conference on Engineering, Project and Production Management, Poland, Bialystok, September 21-23.

Łunarski, J. (2009). Zarządzanie technologiami. Ocena $i$ doskonalenie [Technology management. Evaluation and improvement]. Rzeszów, Poland: Oficyna Wydawnicza Politechniki Rzeszowskiej.

Mazurkiewicz, A., Belina, B., Poteralska, B., Giesko, T., \& Karsznia, W. (2015). Universal methodology for the innovative technologies assessment. Proceedings of the 10th European Conference on Innovation and Entrepreneurship, Genoa, 17-18 September 2015, 458-467.

Pelser, T. G., \& Prinsloo, J. J. (2014). Technology management and the link with technology strategy and company performance. Journal of Global Business and Technology, 10(2), Fall.

Rosenberg, N. (1982). Inside the Black Box. Cambridge, Great Britain: Cambridge University Press.

Santarek, K. (Ed.). (2008). Transfer technologii z uczelni do biznesu. Tworzenie mechanizmów transferu technologii. [Technology transfer from universities to business. Creating mechanisms for technology transfer]. Warszawa, Poland: Polska Agencja Rozwoju Przedsiębiorczości. 
Song, M., Zhao, Y. L., \& Di Benedetto, C. A. (2013). Do perceived pioneering advantages lead to first-mover decisions? Journal of Business Research, 66(8), 11431152. doi: 10.1016/j.jbusres.2012.03.010

Task Force on Management of Technology, National Research Council (U.S.) Cross-Disciplinary Engineering Research Committee; National Research Council (U.S.) Manufacturing Studies Board: Management of Technology: the hidden competitive advantage (1987). Washington, USA: National Academy Press Washington, D.C. 